\title{
Utility of low-copy nuclear markers in phylogenetic reconstruction of Hypericum L. (Hypericaceae)
}

\author{
Andrea Sánchez Meseguer • Isabel Sanmartín • \\ Thomas Marcussen • Bernard E. Pfeil
}

Received: 8 August 2013/Accepted: 20 December 2013/Published online: 19 January 2014

(C) Springer-Verlag Wien 2014

\begin{abstract}
Primers and sequence variation for two lowcopy nuclear genes (LCG) not previously used for phylogenetic inference in the genus Hypericum, PHYC and EMB2765, are presented here in comparison with the fastevolving nuclear intergenic spacer ITS. Substitution rates in the LCG markers were half those reported in ITS for Hypericum, which might help avoid the problems caused by substitution saturation and difficulties to establish homologies that afflict the latter marker. We included representatives of all major clades within Hypericum and found that levels of phylogenetic resolution, clade support values and internal character consistency were similar to, or even higher than, those of ITS-based phylogenies. The presence of at least two copies in EMB2765 in Hypericum imposed a methodological challenge that was circumvented by the design of an effective clade-specific primer. Both EMB2765 and, especially, PHYC appear to be good alternatives to the ITS marker, confirming the main phylogenetic relationships found in previous studies, but with improved resolution and support values for some basal relationships.
\end{abstract}

Keywords Hypericum - Low-copy nuclear genes · Network · Paralogues · Phylogeny

\footnotetext{
A. S. Meseguer $(\varangle) \cdot$ I. Sanmartín

Department of Conservation and Biodiversity, Real Jardín Botanico, CSIC, Plaza de Murillo 2, 28014 Madrid, Spain e-mail: asanchezmeseguer@gmail.com

T. Marcussen · B. E. Pfeil

Department of Biological and Environmental Sciences, University of Gothenburg, Box 100, 40530 Göteborg, Sweden
}

\section{Introduction}

In biosystematics, species phylogenies are generally estimated from gene phylogenies. As the gene phylogenies are contained within the species phylogeny, they represent different levels of organisation and may differ in both topology and relative branch lengths. Processes acting at the gene level, such as gene duplication or incomplete lineage sorting (ILS), or at the species level, such as introgression or hybrid speciation, can produce gene-togene inconsistences or gene-tree/species tree conflicts that may hinder the reconstruction of the species phylogeny (Doyle 1992). This recognition has led to advice in favour of using multiple unlinked data sets in phylogenetic analyses (Small et al. 2004), and to the development of new methods to deal with gene-to-gene inconsistencies, discriminate between different types of gene incongruence, and obtain a more accurate estimation of the species phylogeny, in what is nowadays an active field of research (Meng and Kubatko 2009; Heled and Drummond 2010; Maureira-Butler et al. 2008; Bloomquist and Suchard 2010; Blanco-Pastor et al. 2012). All these methods have in common that they require the use of several independent loci or markers for disentangling the role of alternative biological processes and recovering the species phylogeny.

The nuclear ribosomal intertranscribed spacer ITS is by far the most widely used marker in plant (as well as fungal) systematics because of the facility with which it can be amplified using near-universal primers (White et al. 1990; Baldwin et al. 1995). However, its particular structure, with large tandem arrays of hundreds or thousands of more or less similar copies of which the amplified sequence is a weighted average, can lead to problems of incomplete concerted evolution, associated paralogy issues, and the presence of non-functional pseudogenes (Wendel et al. 
Table 1 Species included in this study and GenBank accession numbers

\begin{tabular}{|c|c|c|c|c|c|c|}
\hline \multirow[t]{2}{*}{ Species } & \multirow[t]{2}{*}{ ID } & \multirow{2}{*}{$\begin{array}{l}\text { Morphological } \\
\text { section }\end{array}$} & \multirow[t]{2}{*}{ References } & \multicolumn{3}{|c|}{ GenBank accessions } \\
\hline & & & & PHYC & EMB & ITS \\
\hline \multicolumn{7}{|l|}{ Hypericeae } \\
\hline H. aegypticum $\mathrm{L}$. & C136 & Adenotrias & Meseguer et al. (2013) & - & KJ123884 & KC709380* \\
\hline H. aethiopicum Thunb. & $\mathrm{C} 110$ & Adenosepalum & Meseguer et al. (2013) & $\begin{array}{l}\text { KJ123856/ } \\
\text { KJ123855 }\end{array}$ & $\begin{array}{l}\text { KJ123878/ } \\
\text { KJ123877 }\end{array}$ & KC709367* \\
\hline H. balearicum $\mathrm{L}$. & C61 & Psorophytum & Meseguer et al. (2013) & KJ123864 & KJ123876 & KC709338* \\
\hline H. balfouri Robson & $\mathrm{C} 171$ & Campylosporus & Meseguer et al. (2013) & $\begin{array}{l}\text { KJ123871/ } \\
\text { KJ123870 }\end{array}$ & - & KC709397* \\
\hline H. canariense $\mathrm{L}$. & $\mathrm{C} 151$ & Webbia & Meseguer et al. (2013) & KJ123866 & KJ123892 & KC709389* \\
\hline H. cerastoides (Spach) Robson & $\mathrm{C} 72$ & Campylopus & Meseguer et al. (2013) & $\begin{array}{l}\text { KJ123862/ } \\
\text { KJ123861 }\end{array}$ & - & KC709341* \\
\hline H. cistifolium Lam. & C177 & Myriandra & Meseguer et al. (2013) & KJ123865 & KJ123886 & KC709402* \\
\hline H. coris $\mathrm{L}$. & $\mathrm{C} 23$ & Coridium & Meseguer et al. (2013) & KJ123867 & - & KC709429* \\
\hline H. elodes L. & C166 & Elodes & Meseguer et al. (2013) & - & KJ123885 & KC709393* \\
\hline H. empetrifolium Willd. & $\mathrm{C} 200$ & Coridium & Meseguer et al. (2013) & - & - & KC709416* \\
\hline H. empetrifolium Willd. & - & Coridium & Davis and Chase (2004) & AY425113* & - & - \\
\hline H. formosum Kunth & $\mathrm{C} 175$ & Hypericum & Meseguer et al. (2013) & $\begin{array}{l}\text { KJ123859/ } \\
\text { KJ123860 }\end{array}$ & - & KC709400* \\
\hline H. grandiflorum Choisy & C146 & Adenosepalum & Meseguer et al. (2013) & $\begin{array}{l}\text { KJ123869/ } \\
\text { KJ123868 }\end{array}$ & KJ123881 & KC709385* \\
\hline H. hypericoides (L.) Crantz & C185 & Myriandra & Meseguer et al. (2013) & - & - & KC709407* \\
\hline H. hypericoides (L.) Crantz & - & Myriandra & Wurdack and Davis (2009) & - & FJ669779* & - \\
\hline H. nummularioides Trautv. & $\mathrm{C} 243$ & Taeniocarpum & Sanchez 164 (MA) & KJ123854 & KJ123880 & - \\
\hline H. peplidifolium Rich & $\mathrm{C} 28$ & Humisfusoid. & Aldasoro 10431 (MA) & KJ123857 & KJ123883 & KJ123872 \\
\hline H. perforatum $\mathrm{L}$. & $\mathrm{C} 56$ & Hypericum & Meseguer et al. (2013) & KJ123858 & - & KC709333* \\
\hline H. reflexum $\mathrm{L}$. & C143 & Adenosepalum & Meseguer et al. (2013) & KJ123863 & KJ123879 & KC709382* \\
\hline H. revolutum Vahl (Schweinf) & $\mathrm{C} 42$ & Campylosporus & Castroviejo 17247 (MA) & KJ123853 & KJ123882 & KJ123873 \\
\hline H. tortuosum Balf. & $\mathrm{C} 170$ & Triadenioides & Aldasoro 14645 (MA) & - & $\begin{array}{l}\text { KJ123891/ } \\
\text { KJ123890 }\end{array}$ & - \\
\hline $\begin{array}{l}\text { Triadenum walterii (Gmel.) } \\
\text { Gleason }\end{array}$ & - & - & Wurdack and Davis (2009) & FJ669909* & FJ669780* & - \\
\hline $\begin{array}{l}\text { Triadenum petiolatum (Pursh) } \\
\text { Britton }\end{array}$ & $\mathrm{C} 16$ & - & Meseguer et al. (2013) & - & - & KC709312* \\
\hline \multicolumn{7}{|l|}{ Vismieae } \\
\hline Vismia glaziovii Ruhland & C192 & - & Meseguer et al. (2013) & - & KJ123852 & KC709411* \\
\hline Vismia $s p$ & C190 & - & Meseguer et al. (2013) & - & - & KC709410* \\
\hline Vismia sp. & - & - & Wurdack and Davis (2009) & FJ669910* & FJ669781* & - \\
\hline \multicolumn{7}{|l|}{ Cratoxyleae } \\
\hline $\begin{array}{l}\text { Cratoxylum formosum Benth. \& } \\
\text { Hook. f. ex Dyer }\end{array}$ & - & - & Wurdack and Davis (2009) & FJ669907* & FJ669777* & - \\
\hline $\begin{array}{l}\text { Cratoxylum formosum Benth. \& } \\
\text { Hook. f. ex Dyer }\end{array}$ & - & - & Nürk et al. (2013) & - & - & HE653674* \\
\hline Eliea articulata Cambess. & C189 & - & $\begin{array}{l}\text { Wurdack and Davis (2009), } \\
\text { Meseguer et al. (2013) }\end{array}$ & FJ669908* & FJ669778* & KC709409* \\
\hline \multicolumn{7}{|l|}{ Outgroups } \\
\hline Byrsonima crassifolia (L.) Kunth & - & - & Davis et al. (2002) & AF500526* & - & - \\
\hline Byrsonima sp. & $\mathrm{C} 152$ & - & Aldasoro 9931 (MA) & - & $\begin{array}{l}\text { KJ123889/ } \\
\text { KJ123888 }\end{array}$ & KJ123874 \\
\hline Clusia gundlachii Stahl & - & - & Davis and Chase (2004) & AY425095* & - & - \\
\hline Croton polyandrus Spreng. & - & - & van Ee et al. (2011) & - & HM564312* & - \\
\hline Euphorbia polychroma $\mathrm{L}$. & - & - & Wurdack and Davis (2009) & - & FJ669757* & - \\
\hline Garcinia sp. & C153 & - & Aldasoro 9930 (MA) & - & KJ123887 & - \\
\hline Garcinia latissima Miq. & - & - & Wurdack and Davis (2009) & - & FJ669743* & - \\
\hline
\end{tabular}


Table 1 continued

\begin{tabular}{|c|c|c|c|c|c|c|}
\hline \multirow[t]{2}{*}{ Species } & \multirow[t]{2}{*}{ ID } & \multirow{2}{*}{$\begin{array}{l}\text { Morphological } \\
\text { section }\end{array}$} & \multirow[t]{2}{*}{ References } & \multicolumn{3}{|c|}{ GenBank accessions } \\
\hline & & & & PHYC & EMB & ITS \\
\hline Pentaphalangium & - & - & Wurdack and Davis (2009) & FJ669891* & - & - \\
\hline Phyllanthus liukiuensis Hayata & - & - & Kawakita and Kato (2009) & FJ235364* & - & - \\
\hline Podostemum ceratophyllum Michx. & - & - & Tippery et al. (2011) & - & - & HM470367* \\
\hline Podostemum ceratophyllum Michx. & - & - & Davis and Chase (2004) & AY425129* & - & - \\
\hline $\begin{array}{l}\text { Rheedia macrophylla (Mart.) } \\
\text { Planch. \& Triana }\end{array}$ & - & - & Davis and Chase (2004) & AY425095* & - & - \\
\hline Viola pubescens Ait. & - & - & Wurdack and Davis (2009) & - & FJ669844* & - \\
\hline Clusia sp. & - & - & MG-2010 & - & - & HM045517* \\
\hline
\end{tabular}

Morphological classification of Hypericum is based on Robson (1977-2010). Herbaria acronyms follow the abbreviations published in the Index Herbariorum

* Sequences obtained from GenBank. GenBank accession numbers for paralogues copies are presented: "paralogue1/paralogue2"

Table 2 Low-copy nuclear regions and sequences of primers screened in this study

\begin{tabular}{|c|c|c|c|}
\hline Region & Primer name & Sequence $5^{\prime}-3^{\prime}$ & References \\
\hline \multirow[t]{4}{*}{ Phytochrome C } & PHYC_Hyp_1F & CCAGCCACCGACATACCTCAAG & Own \\
\hline & PHYC_Hyp_1R & GTAAGCTCCGCCACTTGAC & Own \\
\hline & PHYC-INT1F & CCAGCTACTGATATACCWCARGCTTC & Wurdack and Davis (2009) \\
\hline & PHYC-INTR & CCAGCTTCCATAAGGCTATCAGTRCT & Wurdack and Davis (2009) \\
\hline \multirow[t]{4}{*}{ Chalcone synthetase } & CHS_Hyp_1F & GGAAGAAGTCAGGAAGGCGCAG & Own \\
\hline & CHS_Hyp_1R & GGTCTCAACGGTAAGCCCAG & Own \\
\hline & CHS_Hyp_2F & ACCGTGATGGCCATCGGAAC & Own \\
\hline & CHS_Hyp_2R & CCAAAAAGCACTCCCCACTCGA & Own \\
\hline \multirow[t]{4}{*}{ Chloroplast-expressed glutamine synthetase } & GScp687f & GATGCTCACTACAAGGCTTG & Emshwiller and Doyle (1999) \\
\hline & GScp994r & AATGTGCTCTTTGTGGCGAAG & Emshwiller and Doyle (1999) \\
\hline & GScp853f & TTACYGAACAAGCTGGYGTTGT & Emshwiller and Doyle (1999) \\
\hline & GScp856r & AGSACAACRCCAGCTTGTTC & Emshwiller and Doyle (1999) \\
\hline GBSSI & Wax1f & CTGGTGGACTTGGTGATG & Own \\
\hline \multirow[t]{3}{*}{ Granule-bound starch synthase } & Wax1r & GGCYCCCATDTGRAATCCTGTG & Own \\
\hline & Wax2f & CCTGKCTGCTCTKGARGCAC & Own \\
\hline & Wax2f & CCTTGGCAAGWGGAGCRATCTCS & Own \\
\hline \multirow[t]{2}{*}{ Beta-carotene hydroxylase mRNA } & Chyb_1F & TTG GCARATGGAGGGTGGAGA & Own \\
\hline & Chyb_1R & GGCSTAYATGTTTGTMCAYGAYGG & Own \\
\hline \multirow[t]{5}{*}{ Embryo-defective 2765} & EMB2765ex9F2 & TATCCAAATGAGCAGATTATGTGGGA & Wurdack and Davis (2009) \\
\hline & EMB2765ex9R & TTGGTCCAYTGTGCWGCAGAAGGRT & Wurdack and Davis (2009) \\
\hline & EMB_Hyp_3F & TGATTCCAAAAT TGCCTTGAAG & Own \\
\hline & EMB_Hyp_4F & TGTCCAAGGCRATAGTTACAGTTCTC & Own \\
\hline & EMB_Hyp_3R & CCAGGAAGCTGTCCCACA & Own \\
\hline \multirow[t]{3}{*}{ TAFII15, Salt tolerance during germination 1} & STG_Hyp_1F & CATCCCTGTTGATGGGCTRT & Duarte et al. (2010) \\
\hline & STG_Hyp_1R & GAAATTTGTTGCAGADGTTGC & Duarte et al. (2010) \\
\hline & STG_Hyp_2F & CTTGGACAGATCATCCATNGTCA & Duarte et al. (2010) \\
\hline \multirow[t]{5}{*}{ Glucose-6-phosphate isomerase } & GPI_Hyp_12_1F & CGTGGTGCCACTGTCTCT & Own \\
\hline & GPI_Hyp_16_1R & AGTTGRTAAAAGCTRTGCTG & Own \\
\hline & GPI_Hyp_12_2F & CAATATGGTTTTCCAGTTGTTGA & Own \\
\hline & GPI_Hyp_16_2R & GTTCCAGGTTCACCGAARTC & Own \\
\hline & GPI_Hyp_13_3F & AGGTGCTGCAAGCATTGAT & Own \\
\hline
\end{tabular}


(a)

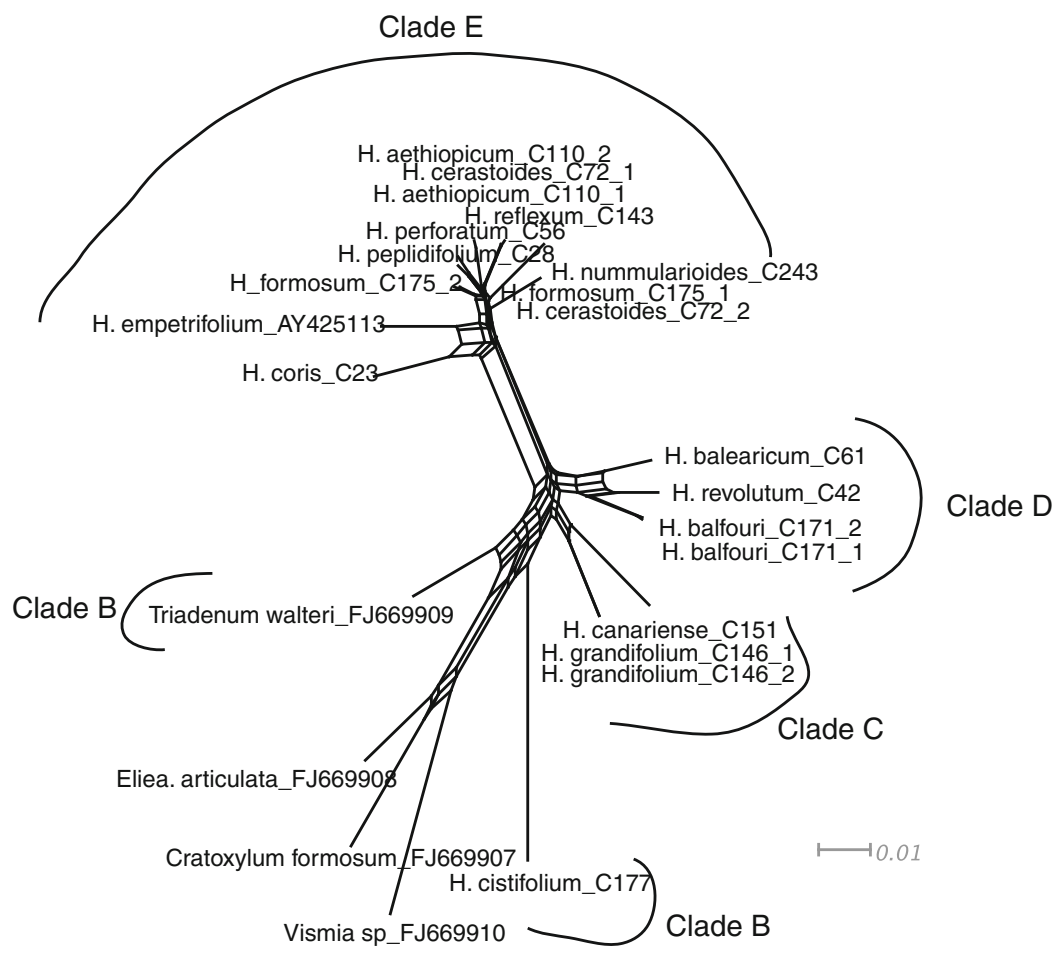

(b)

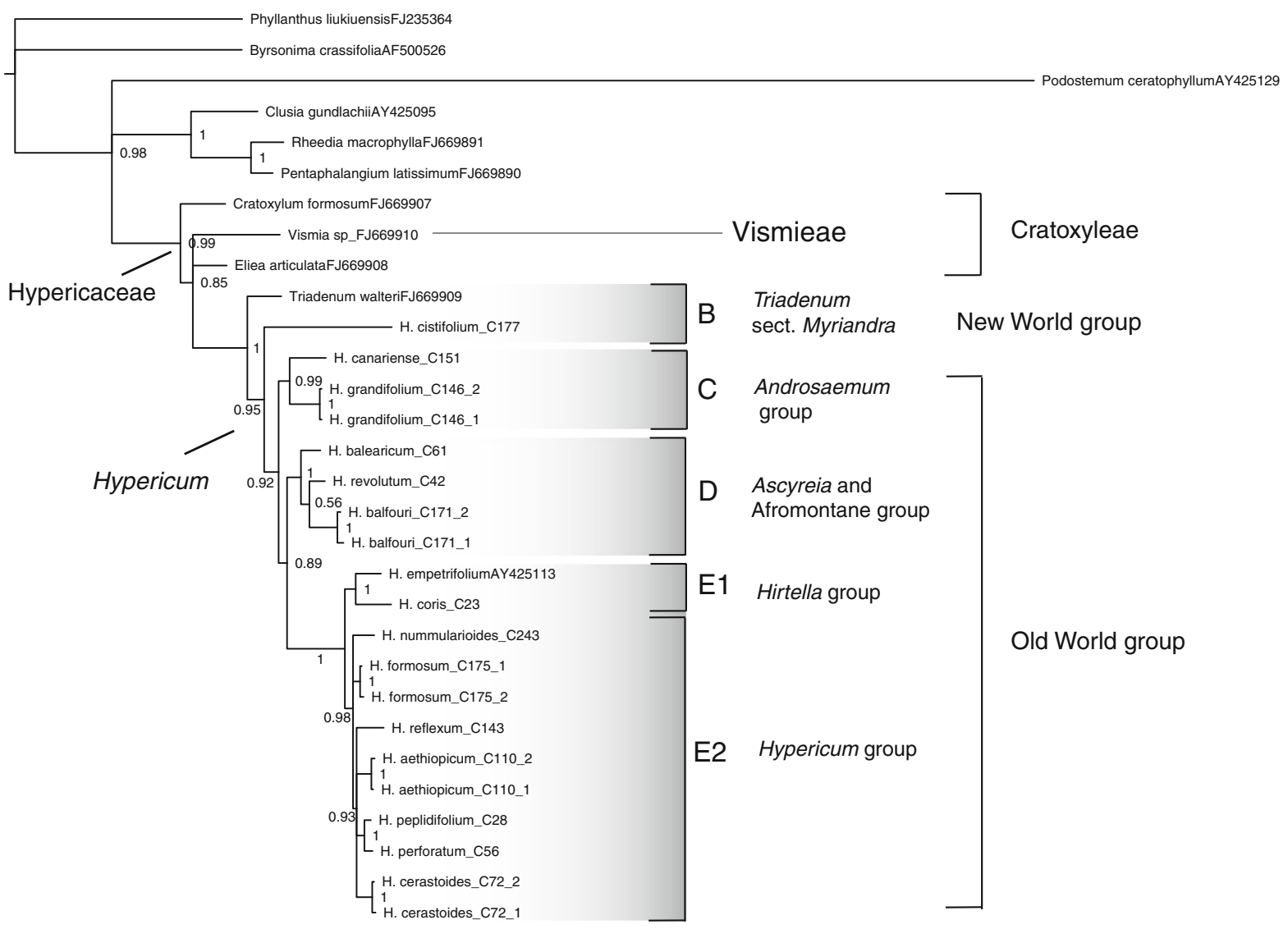


4Fig. 1 a PHYC phylogenetic network in the genus Hypericum. Weight threshold $=0.001$. b Phylogenetic relationships in Hypericum and related taxa inferred from the nuclear PHYC marker. $50 \%$ Bayesian Majority-Rule consensus tree showing posterior probabilities. A to $E$ letters indicate major clades as defined in Meseguer et al. (2013). Podostemum (Podostemaceae), Phyllanthus (Phyllanthacea), Byrsonima (Malpighiaceae), Rheedia, Pentaphalangium and Clusia (Clusiaceae) were used as outgroups

1995; Álvarez and Wendel 2003; Nieto-Feliner and Rosselló 2007, but see Razafimandimbison et al. 2004). Lower thermodynamical stability and a higher rate of mutation than other ribosomal markers can also cause problems in phylogenetic inference (Mayol and Rosselló 2001) or estimation of lineage divergence times (Kay et al. 2006).

Low-copy or single-copy nuclear genes (LCGs) represent a vast but generally unexplored number of unlinked genetic markers rich in phylogenetic information (Sang 2002). LCGs have proven useful to resolve relationships at low taxonomic levels and, unlike the fast-evolving nuclear ITS, are expected to exist in one copy per chromosome set (Crawford and Mort 2004; Small et al. 2004), an assumption that is readily testable as more genomes are sequenced. Nevertheless, nuclear gene families may have complex evolutionary dynamics. For example, duplicate gene copies are frequently found in plant genomes as a consequence of both local (paralogues) and genome-wide (homoeologues) duplication processes (Clegg et al. 1997; Innes et al. 2008). Next to alleles, the occurrence of paralogues or homoeologues creates phylogenetic methodological difficulties, which has made more challenging the extensive use of LCGs in plant systematics (Sang 2002). In the ideal case, a set of primers would amplify a gene at a single locus, making downstream analysis fairly straightforward (allelic variation notwithstanding). However, primers for a gene that is single copy in one clade or pilot study (e.g. Denton et al. 1998) may instead amplify more than one copy in another clade (e.g. Oxelman et al. 2004; Pfeil et al. 2004; Ekenäs et al. 2012), thus making the transfer of existing primers to new groups challenging.

Hypericum L. is the largest genus within the family Hypericaceae. It comprises nearly 500 species of shrubs, small trees or perennial, sometimes annual, herbs, with yellow flowers and frequently glandulous petals, sepals, or leaves (Robson 2012). The present diversity of the genus has been classified in 36 morphological sections distributed worldwide and covering different environments-Hypericum is only absent in the poles, deserts and low-altitude tropical areas (Robson 1981). The most recent systematic revisions included the family Hypericaceae within the informal "clusioid clade" of order Malpighiales, which also includes tropical families such as Clusiaceae, Bonnetiaceae, and Podostemaceae (Davis et al. 2005; Ruhfel et al. 2011). Hypericaceae comprises three tribes: the mainly tropical tribes Vismieae (Vismia, Harungana, and Psorospermum) and Cratoxyleae (Cratoxylum, Eliea), and the cosmopolitan tribe Hypericeae which includes the genera Triadenum, Thornea, Santomasia, Lianthus, and Hypericum (Stevens 2007). Recent molecular results do not support current morphology-based classifications (Stevens 2007) but instead show that Hypericum is paraphyletic to Triadenum, Thornea, and Santomasia (Ruhfel et al. 2011; Nürk et al. 2013; Meseguer et al. 2013). These studies also reject the traditional infrageneric classification and recover many of the large taxonomic sections as non-monophyletic (e.g. Ascyreia, Hirtella, Hypericum, and Brathys). To date, all molecular studies have relied on either chloroplast markers or the nuclear ribosomal ITS marker. Meseguer et al. (2013) compared the phylogenetic signal of these two genomes and found overall congruence, supporting a geographical dichotomy between a New World lineage group and an Old World lineage. The New World lineage comprised the sections Myriandra, Brathys, and Trigynobrathys sister to genus Triadenum, which has been recently synonymised to Hypericum (Ruhfel et al. 2011). The Old World lineage comprised the remaining species and sections of Hypericum, e.g. Ascyreia, Hypericum, Campylosporus, and Hirtella. The Western Palearctic, speciespoor sections Elodes and Adenotrias form the sister group to the New World-Old World clade, although this relation needs to be clarified as it received little support. Meseguer et al. (2013) also reported some cases of incongruence between nuclear and plastid markers, mainly affecting species or species groups, and a general lack of support for both basal and distal relationships in the ITS phylogeny.

Numerous studies suggest that LCGs have the potential to compensate for the lack of resolution and support values of phylogenies based on cpDNA and nrDNA, as well as the ability to recover reticulate phylogenetic relationships (Sang 2002; but see Rauscher et al. 2002). Previous efforts to use LCGs in Hypericum have been limited to two species of pharmacological importance, $H$. perforatum and $H$. androsaemum, to study protein expression in relation to hypericine biosynthesis and the genes encoding it (Liu et al. 2003; Bais et al. 2003; Karppinen and Hohtola 2008). Wurdack and Davis (2009) explored the use of LCGs in resolving phylogenetic relationships within order Malpighiales, and concluded that some of these genes, in particular the rapidly evolving exon 1 of PHYC and exon 9 of EMB2765 in the Populus genome (http://genome.jgipsf.org/Poptr1/Poptr1.home.html), could be useful in the systematics of this order. Here, we evaluate the utility of LCGs in resolving relationships in genus Hypericum, and between Hypericum and its closest relatives, and explore their potential to improve branch support values and resolution in comparison with the nuclear ribosomal ITS marker (Meseguer et al. 2013). We assess levels of 
(a)

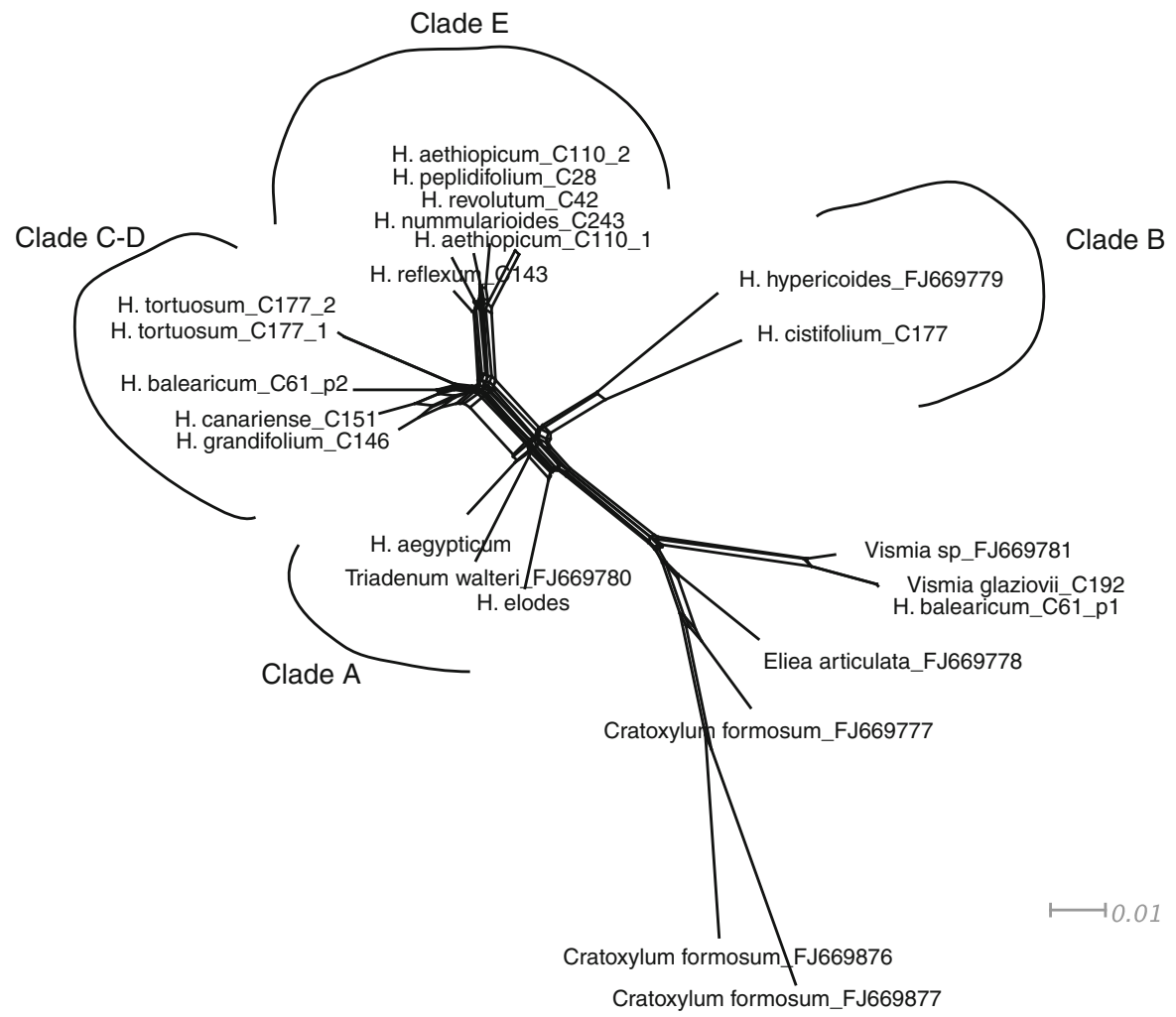

(b)

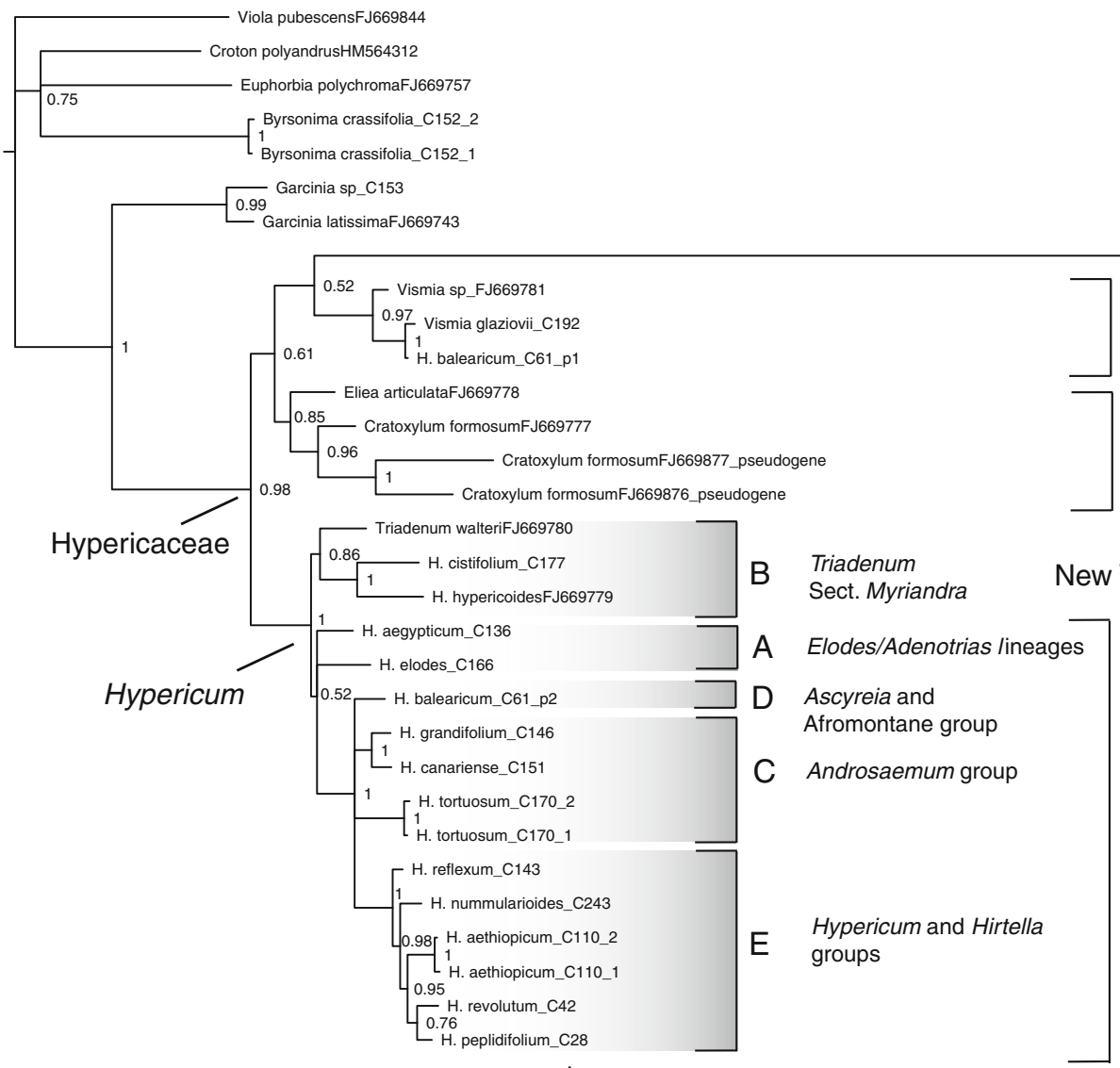

Podostemum ceratophyllumFJ669818

Vismieae

Cratoxyleae

Old World group

0.0 
4Fig. 2 a EMB2765 phylogenetic network in the genus Hypericum. Weight threshold $=0.001$. b Phylogenetic relationships in Hypericum and related taxa inferred from the nuclear EMB2765 marker. $50 \%$ Bayesian Majority-Rule consensus tree showing posterior probabilities. A to $E$ letters indicate major clades as defined in Meseguer et al. (2013). Podostemum (Podostemaceae), Garcinia (Clusiaceae), Byrsonima (Malpighiaceae), Viola (Violaceae), Croton and Euphorbia (Euphorbiaceae) were used as outgroups

variation for the two low-copy nuclear regions PHYC and EMB2765, and present newly developed PHYC primers specific to Hypericum and clade-specific primers to isolate paralogous copies in EMB2765.

\section{Materials and methods}

Taxonomic and gene sampling

Species sampling included representatives of 13 out of 36 morphological sections of Hypericum and focused on representing all major clades within the group (Elodes/ Adenotrias, Myriandra, Brathys s.l., Triadenum, Androsaemum s.l., Afromontane group, Ascyreia s.l., Hirtella s.l., and Hypericum s.1.), as found in a comprehensive phylogenetic analysis of the genus based on ITS and three different plastid markers (trnL-trnF, trnS-trnG, psbA-trnH; Meseguer et al. 2013). The sample also included representatives of closely related genera and families. DNA was extracted from fresh material collected in the field and preserved in silica gel, and from dry material preserved at several herbaria. GenBank accessions from previous studies were also included (Table 1).

\section{Amplification and sequencing}

We initially screened eight low-copy nuclear regions, using primers published in the literature and others newly designed in this study for Hypericum (Table 2). PCR products range from 800 to 1,100 base pairs. The regions were: phytochromeC (PHYC), embryo-defective 2765 (EMB2765, “At2g38770”), chalcone synthase (CHS), waxy (GSSBI), chloroplast-expressed glutamine synthase (ncpGS, GS2, glnII or gln), glucose-6-phosphate isomerase (GPI, "PGIc"), salt tolerance during germination 1 (STG1, TAFII15, "At4 g31720"), and beta-carotene hydroxylase (Chyb). Internal primers designed by Wurdack and Davis (2009) in Malpighiales were initially used to amplify PHYC and EMB2765 markers, but later we designed a new set of PHYC primers specific to Hypericum to increase the length of the amplified region. For EMB2765, we also designed clade-specific primers to isolate paralogous copies. For comparative purposes, we also sequenced the ITS region using primers ITS1 and ITS4 (Aguilar et al. 1999;
White et al. 1990; Table 1). DNA was extracted from leaf tissue samples using the QIAGEN DNeasy plant kit (Qiagen, Hilden, Germany) at the laboratories of the Real Jardín Botánico-CSIC (Madrid, Spain), and following the manufacturer's protocol. The PCR cycling conditions were as follows: $95{ }^{\circ} \mathrm{C}$ for $5 \mathrm{~min}, 35$ cycles of $\left[94^{\circ} \mathrm{C}\right.$ for $30 \mathrm{~s}$, $52{ }^{\circ} \mathrm{C}$ for $30 \mathrm{~s}, 72{ }^{\circ} \mathrm{C}$ for $\left.1.5 \mathrm{~min}\right]$ and a final extension step of 5 min at $72{ }^{\circ} \mathrm{C}$. PCR products were checked on $1 \%$ agarose gels and sequencing was performed at Macrogen, Inc. (Seoul, Korea) using the PCR primers. In all, we generated 44 sequences for 21 species. Several low-copy genes (GBSS, GS2, and STG) did not amplify or showed multiple unspecific bands, indicating low-primer specificity (Table 1). Others, such as GP1, were successfully amplified in a pilot study of a few individuals, but later sequencing indicated high intragenomic polymorphism that would require extensive subcloning to resolve. Only two regions, PHYC and EMB2765, were successfully amplified and sequenced in a majority of taxa. Hence, phylogenetic analysis and discussion of results were based on these regions.

\section{Phylogenetic analysis}

DNA sequences were edited using Sequencher 4.7 (Gene Codes, Ann Arbor, MI). The alignment was done with the online version of MAFFT (Stamatakis et al. 2008, using the L-INS algorithm) and manually adjusted in the editor SeAl v. $2.0 \mathrm{a} 11$ (Rambaut 2002). Although gaps are a potential source of information in phylogenetic analysis, they often exhibit high levels of homoplasy and can be difficult to align, especially when taxon sampling is sparse; therefore, gaps were treated as missing data in the analysis. The alignment is available from the corresponding author. Resulting matrices were analysed under Bayesian inference using MrBayes 3.2cvs (Ronquist et al. 2012), with two parallel runs of four chains each for 2 million generations and sampling every 1,000 generations. Nucleotide substitution models were chosen based on the Akaike Information Criterion (Akaike 1973) as implemented in MrModeltest 2.3 (Nylander 2004). The GTR model was selected for EMB2765, and the HKY model for PHYC, with rate variation among sites in both. We used the program Tracer v.1.5 (Rambaut and Drummond 2003-2009) to verify that all the parameters had reached the stationary phase in log-likelihood values, and the split frequency criterion in MrBayes to assess convergence among chains. The initial 35,000 generations were discarded as burn-in samples and the remaining trees pooled to estimate the posterior probability distribution of the phylogeny and Bayesian clade posterior probabilities (pp).

Evolutionary data are most often presented as a phylogenetic tree with the underlying assumption that evolution 
(a)

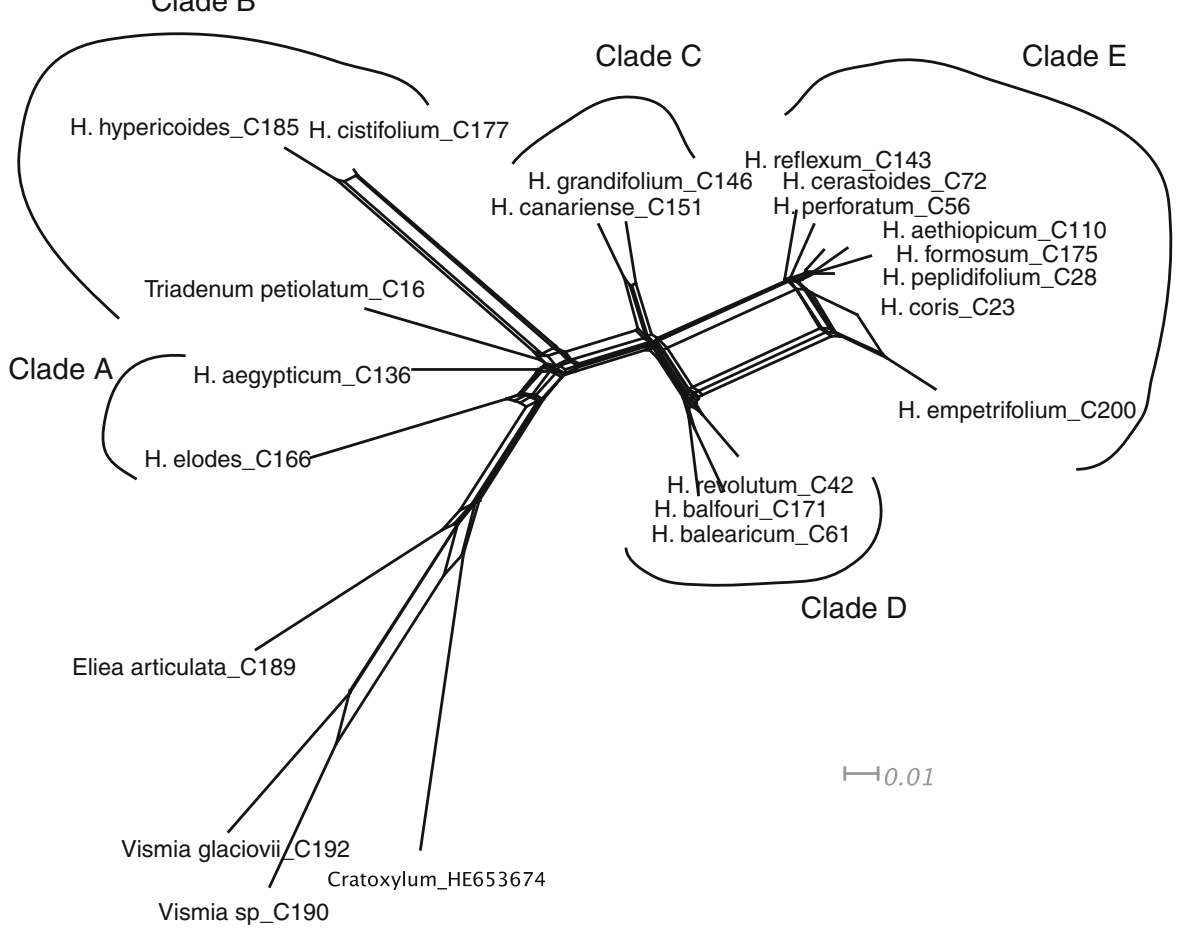

(b)

Byrsonima_C152

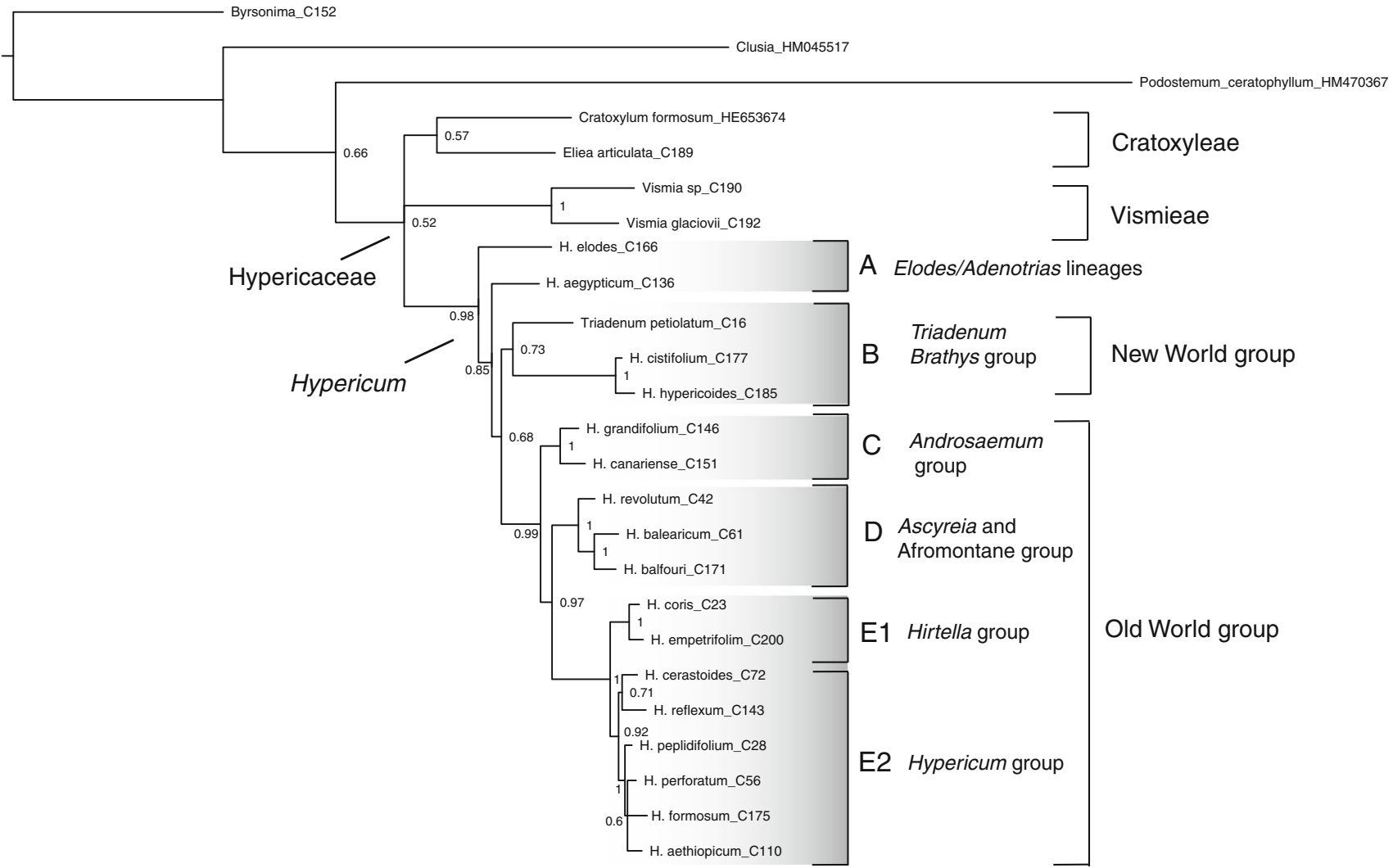

0.0 
4Fig. 3 a ITS phylogenetic network in Hypericum. Weight threshold $=0.001$. b Phylogenetic relationships in the genus Hypericum and related taxa inferred from the nuclear ITS marker. $50 \%$ Bayesian Majority-Rule consensus tree showing posterior probabilities. A to $E$ letters indicate major clades as defined in Meseguer et al. (2013). Podostemum (Podostemaceae), Clusia (Clusiaceae) and Byrsonima (Malpighiaceae) were used as outgroups

is a branching process. However, nuclear markers are subject to different types of recombination-in vivo by meiotic crossing over, i.e. interallele or interlocus, and in vitro during PCR. The probability of observing recombination increases with gene copy number and their similarity. Recombination results in conflicting phylogenetic signals within the sequence and cannot be expressed as a branching topology (Martin et al. 2011). We applied splits networks to visualise phylogenetically ambiguous signals in the alignments that might result from recombination, using the neighbour-net method implemented in SplitsTree v 4.0 (Huson and Bryant 2006) and difference distancebased algorithms to analyse each marker separately. We also used RDP v.3.34 (Martin et al. 2010) to test for possible recombination events in the LCG alignments. This software applies a number of recombination detection and analysis algorithms for detecting putative recombination breakpoints. We used all eight methods available, with a $p$ value of 0.1 with Bonferroni correction to initially provide a low stringency examination of putative breakpoints. We did, however, require phylogenetic evidence for recombination, with internal reference sequences for RDP, with default options for the other methods.

\section{Results and discussion}

Phylogenetic utility of DNA sequence loci

Not every taxon analysed could be sequenced for all markers. Most technical difficulties were apparently related to low primer specificity owing to base mismatches in the primer site. The amplification sometimes yielded multiple bands and after sequencing we occasionally found polymorphic sites. We excluded specimens with multiple signals excepting those with single polymorphic sites; in such cases, we resolved the polymorphy by creating two sequences. Split networks showed a small number of contradictory characters (visualised as a box in the figure) in all three markers analysed (Figs. 1, 2, 3a), but RDP did not detect significant $(p \leq 0.05)$ evidence of recombination in any of the markers.

Levels of sequence variation varied between loci (Table 3). ITS had the highest number of parsimony informative characters and number of variable characters. The two nuclear exons EMB2765 and PHYC exhibited similar levels of variation to one another, exceeding those reported in Hypericum for some commonly used fastevolving chloroplast spacers (Meseguer et al. 2013). On the other hand, substitution rates for the LCGs were half those of ITS (Table 3). Meseguer et al. (2013) reported high rates of nucleotide substitution in the ITS ribosomal spacer, which made alignment, especially with outgroups, exceptionally difficult probably owing to saturation (Meseguer et al. 2013). Alignment was considerably more straightforward in EMB2765 and PHYC, which, together with good phylogenetic support and levels of resolution (see below), make these LCGs a good alternative to ITS in Hypericum phylogenetic inference. This agrees with Wurdack and Davis (2009) who found PHYC and EMB2765 to be useful markers for sequencing across a range of Malphigiales and more distant outgroups. Exploring a far deeper phylogeny than ours, the authors had excluded the third codon position in their analyses; analysing our data with or without this position resulted in the same phylogenetic topologies.

Character consistency within each marker was calculated using the consistency and retention indices (CI and RI, respectively; Table 3) based on the Bayesian topologies in PAUP*v4.0b10 (Swofford 2002). This showed that the RI within EMB2765 is comparable to that found in ITS, whereas the $\mathrm{CI}$ is more favourable in EMB2765 than in ITS. Within PHYC, the two indices have scores that are considerably better than those found in ITS (Table 3).

Phylogenetic relationships

The Bayesian $50 \%$ majority-rule consensus trees for PHYC, EMB2765 and ITS are given in Figs. 1b, 2b and 3b, respectively. Comparison among the three phylogenies is not straightforward because of amplification failure in some of the taxa. However, the LCG phylogenies (Figs. 1b, 2b) are largely congruent with the ITS tree (Fig. 3b) and with those reported in previous molecular studies of Hypericum (Ruhfel et al. 2011; Nürk et al. 2013; Meseguer et al. 2013; Park and Kim 2004; Crockett et al. 2004). Splits networks showed similar groupings (Figs. 1a, 2, 3a). LCGs presented higher support values for some basal nodes than those of ITS (Fig. 3; Meseguer et al. 2013; Nürk et al. 2013; Park and Kim 2004; Crockett et al. 2004) or plastid phylogenies (Meseguer et al. 2013). Among the studied LCGs, resolution and clade support values were highest in the PHYC phylogeny (Fig. 1). The PHYC phylogeny (Fig. 1) shows a geographic dichotomy between the New World lineage (H. cistifolium) and an Old World lineage, the latter divided into several clades that generally correspond to those found by Meseguer et al. (2013) and Nürk et al. (2013): clade C (Androsaemum group), clade D (Ascyreia and Afromontane groups) and clade $\mathrm{E}$. Within the latter, two subclades can be 
Table 3 Character status summary for the nuclear low-copy markers PHYC and EMB2765, and for the nuclear intergenic spacer ITS

\begin{tabular}{|c|c|c|c|c|c|c|c|}
\hline Region & $\begin{array}{l}\text { \# Of } \\
\text { characters }\end{array}$ & $\begin{array}{l}\text { \# Parsimonious } \\
\text { uninformative }\end{array}$ & $\begin{array}{l}\text { \# Parsimonious } \\
\text { informative }\end{array}$ & $\begin{array}{l}\% \text { Informative } \\
\text { characters }\end{array}$ & TL mean & CI & RI \\
\hline EMB2765 & 819 & 105 & 89 & 10.86 & 1.822462 & 0.782 & 0.749 \\
\hline PHYC & 822 & 103 & 94 & 11.43 & 2.047945 & 0.853 & 0.879 \\
\hline ITS & 740 & 105 & 164 & 22.16 & 3.929994 & 0.729 & 0.759 \\
\hline
\end{tabular}

$T L$ mean mean of the total tree length estimated over the two independent Bayesian runs, $C I$ consistency index, $R I$ retention index

distinguished: the Hirtella group (clade E1) and the larger Hypericum group (clade E2, Meseguer et al. 2013), although the last showed little internal resolution. The EMB phylogeny showed generally lower support values for basal relationships but slightly better resolution at species level (clade E2) than PHYC. This marker also recovers Triadenum walteri (=Hypericum walteri) as part of the New World lineage, confirming other phylogenetic studies that found Hypericum to be non-monophyletic (Meseguer et al. 2013; Nürk et al. 2013; Ruhfel et al. 2011). In contrast, the PHYC phylogeny shows Hypericum walteri as the sister group of Hypericum, although this relationship is not well supported. Other incongruences between the two LCG markers affect phylogenetic relationships at the tribal level. In PHYC, the family Hypericaceae and the tribe Hypericeae are both recovered as well-supported monophyletic groups, whereas tribe Cratoxyleae (Cratoxylum formosum and Eliea articulata) appears as non-monophyletic (Fig. 1). In the EMB2765 tree, tribal relationships are better resolved, with tribe Hypericeae sister to Cratoxyleae-Vismieae. However, one species of Hypericum, H. balearicum, appears within tribe Vismieae, as sister group to Vismia (Fig. 2). The anomalous position of this sequence in the EMB2765 tree could be attributed to incomplete lineage sorting or to an ancient duplication event in which a different paralogue has been amplified in $H$. balearicum. The long branch separating the specimen $H$. balearicum_C61_p1 from the rest of Hypericum, and the short branch between this species and the outgroup Vismia, supports the later explanation as the most probable. To solve this issue, we designed a new internal primer for EMB based on the right Hypericum sequences to recover the orthologous copy of this marker in $H$. balearicum. The new sequence $H$. balearicum_C61_p2 was resolved in a congruent position with the other markers in the phylogeny (Fig. 2), lending support to the hypothesis that EMB2765 is present in more than one copy in Hypericum. Only diploid specimens have been described in H. balearicum (Robson, 1985), suggesting that intragenomic polymorphism probably owed to local duplications (paralogues). Further cloning strategies could help to do a better screening of gene copies. Nevertheless, our study suggests that the design of copy-specific primers can also be a useful strategy to address paralogy. Interestingly,
Wurdack and Davis (2009) found non-functional pseudogene copies of EMB in Cratoxylum (Hypericaceae, Fig. 2), but these shorter copies grouped with the functional, fulllength sequence (and were isolated using the same primers), suggesting a more recent duplication event.

\section{Conclusions}

Our study, including representatives from all major clades of Hypericum, shows the potential of two LCGs, EMB2765 and PHYC, for reconstructing phylogenetic relationships in genus Hypericum and related clades. A lower mutation rate in these markers in comparison with the ITS ribosomal spacer makes it easy to establish homologies in the alignment with outgroups. In addition, pilot phylogenetic studies showed improved resolution and clade support values for basal nodes compared with ITS and other fast-evolving plastid markers. Further, the internal character consistency of the new markers is comparable to, or better than, that found in ITS. In this study, we have also discovered a paralogous copy in EMB2765 for Hypericum that was isolated through the design of copy-specific primers.

Acknowledgments This work was funded by the Spanish Ministry of Education and Science (projects CGL2009-13322-C03-01/BOS and CGL2012-40129-C02-01) to I.S. and a PhD research grant AP2007-01698 to A.S.M. B.E.P. is supported by grants from the Swedish Research Council, the Royal Swedish Academy of Sciences, Lars Hiertas Minne fund, The Royal Physiographic Society in Lund, Helge Ax:son Johnsons fund and the Lundgrenska fund. The authors are grateful to B. Oxelman, Y. Bertrand, A. Hilpold and F. De Sousa for help at different stages of this research.

\section{References}

Aguilar JF, Rosselló JA, Feliner GN (1999) Molecular evidence for the compilospecies model of reticulate evolution in Armeria (Plumbaginaceae). Syst Biol 48:735-754

Akaike H (1973) Information theory and an extension of the maximum likelihood principle. In: Kiado A (ed.) Second international symposium on information Theory. Budapest, pp 267-281

Álvarez I, Wendel JF (2003) Ribosomal ITS sequences and plant phylogenetic inference. Mol Phylogenetics Evol 29:417-434 
Bais HP, Vepachedu R, Lawrence CB, Stermitz FR, Vivanco JM (2003) Molecular and biochemical characterization of an enzyme responsible for the formation of hypericin in St. John's wort (Hypericum perforatum L.). J Biol Chem 278:32413-32422

Baldwin BG, Sanderson MJ, Porter JM, Wojciechowski MF, Campbell CS, Donoghue MJ (1995) The ITS region of nuclear ribosomal DNA-A valuable source of evidence on angiosperm phylogeny. Ann Missouri Bot Gard 82:247-277

Blanco-Pastor JL, Vargas P, Pfeil BE (2012) Coalescent simulations reveal hybridization and incomplete lineage sorting in Mediterranean Linaria. Plos One 7:e39089

Bloomquist EW, Suchard MA (2010) Unifying vertical and nonvertical evolution: a stochastic arg-based framework. Syst Biol 59:27-41

Crawford DJ, Mort ME (2004) Single-locus molecular markers for inferring relationships at lower taxonomic levels: observations and comments. Taxon 53:631-635

Clegg MT, Cummings MP, Durbin ML (1997) The evolution of plant nuclear genes. Proc Natl Acad Sci USA 92:7791-7798

Crockett SL, Douglas AW, Scheffler BE, Khan IA (2004) Genetic profiling of Hypericum (St. John's wort) species by nuclear ribosomal ITS sequence analysis. Pl Med 70:1-7

Davis CC, Chase MW (2004) Elatinaceae are sister to Malpighiaceae; Peridiscaceae belong to Saxifragales. Am J Botany 91:262-273

Davis CC, Bell CD, Mathews S, Donoghue MJ (2002) Laurasian migration explains Gondwanan disjunctions: evidence from Malpighiaceae. Proc Natl Acad Sci USA 99:6833-6837

Davis CC, Webb CO, Wurdack KJ, Jaramillo CA, Donoghue MJ (2005) Explosive radiation of Malpighiales supports a midCretaceous origin of modern tropical rain forests. American Naturalist 165:E36-E65

Denton AL, McConaughy BL, Hall BD (1998) Usefulness of RNA polymerase II coding sequences for estimation of green plant phylogeny. Mol Biol Evol 15:1082-1085

Doyle JJ (1992) Gene trees and species trees: molecular systematics as one-character taxonomy. Syst Bot 17:144-163

Duarte J, Wall PK, Edger P, Landherr L, Ma H, Pires JC, LeebensMack J (2010) Identification of shared single copy nuclear genes in Arabidopsis, Populus, Vitis and Oryza and their phylogenetic utility across various taxonomic levels. BMC Evol Biol 10:61

Ekenäs C, Heidari N, Andreasen K (2012) Arnica (Asteraceae) phylogeny revisited using RPB2: Complex patterns and multiple d-paralogues. Mol Phylogenet Evol 64:261-270

Emshwiller E, Doyle JJ (1999) Chloroplast-expressed glutamine synthetase (ncpGS): potential utility for phylogenetic studies with an example from Oxalis (Oxalidaceae). Mol Phylogenet Evol 12:310-319

Heled J, Drummond AJ (2010) Bayesian inference of species trees from multilocus data. Mol Biol Evol 27:570-580

Huson DH, Bryant D (2006) Application of phylogenetic networks in evolutionary studies. Mol Biol Evol 23:254-267

Innes RW, Ameline-Torregrosa C, Ashfield T, Cannon E, Cannon SB, Chacko B, Chen NWG, Couloux A, Dalwani A, Denny R et al (2008) Differential accumulation of retroelements and diversification of NB-LRR disease resistance genes in duplicated regions following polyploidy in the ancestor of soybean. Plant Physiol 148:1740-1759

Karppinen K, Hohtola A (2008) Molecular cloning and tissue-specific expression of two cDNAs encoding polyketide synthases from Hypericum perforatum. J Plant Physiol 165:1079-1086

Kawakita A, Kato M (2009) Repeated independent evolution of obligate pollination mutualism in the Phyllantheae-Epicephala association. Proc Biol Sci 276:417-426

Kay KM, Whittall JB, Hodges SA (2006) A survey of nuclear ribosomal internal transcribed spacer substitution rates across angiosperms: an approximate molecular clock with life history effects. BMC Evol Biol 6:36. doi:10.1186/1471-2148-6-36

Liu B, Falkenstein-Paul H, Schmidt W, Beerhues L (2003) Benzophenone synthase and chalcone synthase from Hypericum androsaemum cell cultures: cDNA cloning, functional expression, and site-directed mutagenesis of two polyketide synthases. Plant J 34:847-855

Martin DP, Lemey P, Lott M, Moulton V, Posada D, Lefeuvre P (2010) RDP3: a flexible and fast computer program for analyzing recombination. Bioinformatics 26:2462-2463

Martin DP, Lemey P, Posada D (2011) Analysing recombination in nucleotide sequences. Mol Ecol Resour 11:943-955

Mayol M, Rosselló JA (2001) Why nuclear ribosomal DNA spacers (ITS) tell different stories in Quercus. Mol Phylogenet Evol 19:167-176

Maureira-Butler IJ, Pfeil BE, Muangprom A, Osborn TC, Doyle JJ (2008) The reticulate history of Medicago (Fabaceae). Syst Biol $57: 466-482$

Meng C, Kubatko LS (2009) Detecting hybrid speciation in the presence of incomplete lineage sorting using gene tree incongruence: a model. Theor Popul Biol 75:35-45

Meseguer AS, Aldasoro JJ, Sanmartín I (2013) Bayesian inference of phylogeny, morphology and range evolution reveals a complex evolutionary history in St John's wort (Hypericum). Mol Phylogenet Evol 67:379-403

Nieto-Feliner G, Rosselló JA (2007) Better the devil you know? Guidelines for insightful utilization of nrDNA ITS in specieslevel evolutionary studies in plants. Mol Phylogenet Evol 44:911-919

Nürk NM, Madriñán S, Carine MA, Chase MW, Blattner FR (2013) Molecular phylogenetics and morphological evolution of St. John's wort (Hypericum; Hypericaceae). Mol Phylogenet Evol 66:1-16

Nylander JAA (2004) MrModeltest v2. Program distributed by the author. Evolutionary Biology Centre, Uppsala University

Oxelman B, Yoshikawa N, McConaughy BL, Luo J, Denton AL, Hall BD (2004) RPB2 gene phylogeny in flowering plants, with particular emphasis on asterids. Mol Phylogenet Evol 32:462-479

Park SJ, Kim KJ (2004) Molecular phylogeny of the genus Hypericum (Hypericaceae) from Korea and Japan: Evidence from nuclear rDNA ITS sequence data. J Plant Biol 47:366-374

Pfeil BE, Brubaker CL, Craven LA, Crisp MD (2004) Paralogy and orthology in the Malvaceae rpb2 gene family: investigation of gene duplication in Hibiscus. Mol Biol Evol 21:1428-1437

Rambaut A, Drummond AJ (2003-2009) Tracer, version 1.5, MCMC trace analysis package. http://tree.bio.ed.ac.uk/software/

Rambaut A (2002) Se-Al: Sequence Alignment Editor. Available from http://tree.bio.ed.ac.uk/software/seal/

Rauscher JT, Doyle JJ, Brown AH (2002) Internal transcribed spacer repeat-specific primers and the analysis of hybridization in the Glycine tomentella (Leguminosae) polyploid complex. Mol Ecol 11:2691-2702

Razafimandimbison SG, Kellogg EA, Bremer B (2004) Recent origin and phylogenetic utility of divergent ITS putative pseudogenes: a case study from Naucleeae (Rubiaceae). Syst Biol 53:177-192

Robson NKB (1981) Studies in the genus Hypericum L. (Guttiferae). 2. Characters of the genus. Bull Brit Mus (Nat Hist) Bot 8:55-226

Robson NKB (1985) Studies in the genus Hypericum L. (Guttiferae). 3. Sections 1. Campylosporus to 6a. Umbraculoides. Bull Brit Mus (Nat Hist) Bot 12:163-211

Robson NKB (2012) Studies in the genus Hypericum L. (Hypericaceae) 9. Addenda, corrigenda, keys, lists and general discussion. Phytotaxa 72:1-111 
Ronquist F, Teslenko M, Van Der Mark P, Ayres DL, Darling A, Hpohna S, Larget B, Liu L, Suchard MA, Huelsenbeck JP (2012) MrBayes 3.2: efficient Bayesian phylogenetic inference and model choice across a large model space. Syst Biol 61:539-542

Ruhfel BR, Bittrich V, Bove CP, Gustafsson MHG, Philbrick CT, Rutishauser R, Xi Z, Davis CC (2011) Phylogeny of the clusioid clade (Malpighiales): Evidence from the plastid and mitochondrial genomes. Am J Bot 98:306-325

Sang T (2002) Utility of low-copy nuclear gene sequences in plant phylogenetics. Crit Rev Biochem Mol Biol 37:121-147

Small RL, Cronn RC, Wendel JF (2004) L. A. S. Johnson review no. 2. Use of nuclear genes for phylogeny reconstruction in plants. Austral Syst Bot 17:145-170

Stamatakis A, Hoover P, Rougemont J (2008) A rapid bootstrap algorithm for the RAxML web servers. Syst Biol 57:758-771

Stevens PF (2007) Hypericaceae. In: Kubitzki K (ed) The families and genera of vascular plants. Springer, Berlin, pp 194-201
Swofford DL (2002) PAUP*: phylogenetic analysis using parsimony (* and other methods)

Tippery NP, Philbrick CT, Bove CP, Les DH (2011) Systematics and phylogeny of neotropical Podostemaceae. Syst Bot 36:105-118

van Ee BW, Riina R, Berry PE (2011) A revised infrageneric classification and molecular phylogeny of New World Croton (Euphorbiaceae). Taxon 60:791-823

Wendel JF, Schnabel A, Seelanan T (1995) Bidirectional interlocus concerted evolution following allopolyploid speciation in cotton (Gossypium). Proc Natl Acad Sci USA 92:280-284

White TJ, Bruns T, Lee S, Taylor J (1990) Amplification and direct sequencing of fungal ribosomal RNA genes for phylogenetics. PCR protocols: a guide to methods and applications, 315-322

Wurdack KJ, Davis CC (2009) Malpighiales phylogenetics: gaining ground on one of the most recalcitrant clades in the angiosperm tree of life. Am J Bot 96:1551-1570 